\title{
IDENTIFICATION OF UROVIRULENT MARKERS IN UROPATHOGENIC ESCHERICHIA COLI.
}

\author{
N. Padmaja, Anand Acharya, P. Nageswar Rao
}

1. Assistant Professor, Department of Microbiology, Konaseema Institute of Medical Science, Amalapuram, Andhra Pradesh.

2. Associate Professor, Department of Pharmacology, Konaseema Institute of Medical Science, Amalapuram, Andhra Pradesh.

3. Professor \& Head, Department of Microbiology, Konaseema Institute of Medical Science, Amalapuram, Andhra Pradesh.

\section{CORRESPONDING AUTHOR}

Dr. Anand Acharya,

KIMS Hospital, Amalapuram,

Andhra Pradesh.

E-mail: anand_kims@yahoo.co.in,

Ph: 009109963598050.

ABSTRACT: The present study was conducted in the Department of Microbiology, Konaseema Institute of Medical Sciences, Amalapuram, East Godavari District from August 2011 to January 2012. Fifty Escherichia coli (E.coli) strains isolated from urine samples of different clinical entities and 25 feacal isolates were studied for the detection of virulence markers of E.coli. There are 27 uropathogenic E.coli (UPEC) isolates from 50 E.coli \& 5 UPEC from 25 controls. Among isolates tested the most common virulent marker is haemolysin 21 (42\%), followed by Mannose resistant haemagglutination 16 (32\%), cell surface hydrophobicity 13 (26\%). In this, there are 14 cases with only one virulence marker, 8 with 2 marker combinations and 15 cases with combination of 3 markers.

KEY WORDS: Uropathogenic Escherichia coli, Urovirulent Markers, Urinary Tract Infection (UTI)

INTRODUCTION: UTI is one of the most important causes of morbidity and mortality. E.coli is the most frequent urinary pathogen isolated from $50 \%-90 \%$ of all uncomplicated urinary tract infections. It is now recognized that there are subsets of faecal E.coli which can colonize periurethral area, enter urinary tract and cause symptomatic diseases. These are currently defined as Uropathogenic E.coli. It has been traditionally described that certain serotypes of E.coli were consistently associated with uropathogenicity and were designated as uropathogenic E.coli. These isolates express chromosomally encoded virulence markers. The virulence factors include different adhesins, haemolysin production, haemagglutination, cell surface hydrophobicity. The present study was designated to determine the urovirulence factors of E.coli isolated from the patients of UTI and to study their antimicrobial susceptibility pattern.

MATERIALS AND METHODS: The study was conducted in the Department of Microbiology, KIMS, Amalapuram, East Godawari from August 2011 to January 2012. 50 E.coli strains isolated from urine samples \& 25 faecal isolates were studied for 1 . $\alpha$ Haemolysin on $5 \%$ sheep blood agar. 2. Mannose Resistant Haemagglutination. 3. Cell surface hydrophobicity. 4. Antibiotic susceptibility testing by Kirby - Bauyer disc diffusion method. 
INCLUSION CRITERIA: Adult patients with UTI attending various clinical departments of KIMS and adult healthy individuals for stool samples are taken.

SAMPLES: 1. Clean catch midstream urine samples from the patients (50). 2. Stool samples of adult healthy individuals (25)

COLLECTION AND CULTURE OF SAMPLE: Sample is transported to Microbiology lab with in half an hour and processed by 1. Wet film preparation. 2. Culturing on Mac Conkey's agar, Blood agar \& CLED agar medium \& incubated aerobically at $370 \mathrm{C}$ for $24 \mathrm{hrs}$. 3. Growth on plates and significant bacterial count. i.e. more than $10^{5}$ colonies / ml. urine and tested for further identification of E.coli by various biochemical reactions. Such E.coli were screened for virulence markers.

HAEMOLYSIN: For detecting haemolysin, 5\% sheep B.A is used and a zone of lysis around each colony is observed after overnight incubation at $37^{\circ} \mathrm{C}$, if haemolysin is produced.

MANNOSE SENSITIVE HAEMAGGLUTINATION: HA is detected by clumping of erythrocytes by bacterial fimbriae in the presence of D-Mannose. The test was carried out as per the direct bacterial HA test slide method and mannose sensitive and resistant HA tests. HA was considered when it occurred in the presence of $2 \% \mathrm{D}$ - Mannose and Mannose sensitive, when it was inhibited by D-Mannose.

CELL SURFACE HYDROPHOBICITY: This was done by Salt Aggregation test. Strains are considered hydrophobic, if they are aggregated in concentration of $<1.4 \mathrm{M}$. Ammonium sulphate.

ANTIBIOTIC SUSCEPTIBILITY TESTING: This was performed on all isolates of E.coli by KirbyBauer`s disc diffusion method on Muller Hinton agar.

RESULTS: Of the 50 patients, 0 - 15 age group comprised of 11 persons, 16 - 40 age group comprised of 18 persons and $>40$ years group comprised of 21 persons. Females (30) are more than male (20) patients. Among various clinical entities, 30 cases presented with lower UTI (60\%), 14 cases with asymptomatic bacteriuria (28\%) and 6 with pyelonephritis (12\%).

Among 50 cases tested 27 (54\%) were positive for virulence markers and out of 25 controls, $5(20 \%)$ were positive for virulence markers. Among the isolates tested, the most common virulent marker is Haemolysin 21 (42\%) followed by Mannose Resistant Haemagglutination (MRHA) 16 (32\%) and Cell Surface Hydrophobicity (CSH) 13 (26\%). In control group, the occurrence of Haemolysin was 1 (20\%), MRHA 3 (60\%), CSH 1 (20\%). (Note: Percentage calculated as per total 50 isolates). There are 14 cases positive for 1 marker, 8 cases positive for 2 markers and 5 cases positive for 3 markers.

$41 \%$ isolates were sensitive to Amikacin, $78 \%$ to Nitrofurantoin, $72 \%$ sensitive to Cefotaxime, $52 \%$ to Cephalexin, $46 \%$ to Co-trimoxazole. High resistance is seen for Norfloxacin $80 \%$ followed by Ampicillin 73\%, Cefuroxime 68\%. (Note: Percentage drug sensitivity and resistance pattern calculated for total number of 50 strains isolated). 


\section{No. Of Positive Virulence Markers - Table I}

\begin{tabular}{|c|c|c|c|}
\hline Composition & No. of Tested & Positive virulence markers & $\%$ \\
\hline Cases & 50 & 27 & $54 \%$ \\
\hline Control & 25 & 5 & $20 \%$ \\
\hline
\end{tabular}

\section{Antibiotic Sensitivity Test - Table II}

\begin{tabular}{|c|l|c|c|c|c|}
\hline S.No. & Drug & Sensitivity & $\%$ & Resistant & $\%$ \\
\hline 1 & Amikacin & 41 & $82 \%$ & 9 & $18 \%$ \\
\hline 2 & Nitrofurantoin & 39 & $78 \%$ & 11 & $22 \%$ \\
\hline 3 & Cefotaxime & 36 & $72 \%$ & 14 & $28 \%$ \\
\hline 4 & Cephalexin & 26 & $52 \%$ & 21 & $48 \%$ \\
\hline 5 & Co-trimoxazole & 23 & $46 \%$ & 27 & $54 \%$ \\
\hline 6 & Cefuroxime & 16 & $32 \%$ & 34 & $68 \%$ \\
\hline 7 & Ampicillin & 13 & $26 \%$ & 37 & $74 \%$ \\
\hline 8 & Norfloxacin & 10 & $20 \%$ & 40 & $80 \%$ \\
\hline
\end{tabular}

DISCUSSION: Considering the high degree of morbidity in urinary tract infection the uropathogenic E.coli is receiving the more attention. The present study was undertaken to study the virulence factors namely Haemolysin, MRHA and CSH. 50 E.coli isolates from urine of cases with clinically diagnosed UTI are taken as study group and 25 E.coli from faeces of healthy persons as control group. The high incidence of UTI was observed above 40 years age group followed by 16-40 years age group. This is because; the elderly patients are likely to be predisposed to conditions like 1. Urinary tract obstruction. 2. Poor bladder emptying 3. Diabetes and 4. Prostate enlargement in elderly males. These factors favour colonization of bacteria and play an important role in UTI.

High incidence of UTI is observed in females (30) than in males (20), which is due to 1. Short urethra and 2. Close proximity of urethra to perianal region.

Regarding AST, most of the isolates are sensitive to Amikacin (82\%) and Nitrofurantoin (78\%). Whereas most of the isolates are resistant to Norflox, Ampicillin, Cefuroxime and Cephalexin. This shows that Aminoglycosides and Nitrofurantoin are useful for most of UTI and high level of resistance indicates the lack of rational drug use. In view of emerging resistance antimicrobial therapy should be started after culture sensitivity report. This will prevent the development of resistance of bacteria towards important antibiotic and we will have choice of antimicrobial agent for complicated urinary tract infection. 


\section{REFERENCES:}

1. Orskov, F.1984, Genus I.Escherichia castellani and Chalmers 1919. In: Krieg, N.and Holt, J.G. (eds), Bergey`s Manual of systemic bacteriology. London: Williams \& Wilkins, 42023.

2. Smith HW. The haemolysins of Eschericha coli. J. Pathol Bacteriology 1963; 85: 197-211.

3. Kaijser B.Immunology of Escherichia coli. K. Antigen and its relations to UTI. J. Infectious diseases 1973; 127:672-77.

4. Quackenbush RL, Falkow S. Relationship between colicin V activity and virulence in E.coli. Infect Immune 1979;24:562-64.

5. Hageberg L, Jodal U, Korhonen Tk, Lidin - Janson G, Lindberg U, Svanborg Eden C. Adhension, haemagglutination and virulence of E.coli causing Urinary track infections. Infect Immune 1981;31:564-70.

6. Lindahl M, Faris A, Wadstrom T, Hjerten S. A new test based on salting out to measure relative surface hydrophobicity of bacterial cells. Biochim Biophys Acta 1981;677:47176

7. Orskov I, Orskov F, Birch-Andersen A, Kananmori M, Svanborg-Eden C, O, K, H and fimbrial antigens in E.coli serotypes associated with pyelonephritis and cystitis. Scand J Infectious diseases 1982; Suppl 33:18-25.

8. Cavalieri SJ, Bohach GA, Snyder IS. E.coli alpha haemolysin: Characteristics and probable role in pathogenicity. Microbiol Rev 1984;48:326-43.

9. Holmes, B and Gross, R.J. 1990. Coliform bacteria: various other members of the Enterobacteriaceae. In: Parker, M.T. and Collier, L.H. (eds), Topley \& Willson`s Principles of bacteriology, Virology and Immunity, 8th $^{\text {th }}$. London: Edward Arnold, 415-41.

10. Siegfried L, Marta K, HanaP, Molokacova M and Filika J. Virulence-associated factors in E.coli strains isolated from children with urinary tract infections. Journal of Medical Microbiology 1994;41: 127-32.

11. Johnson J: Microbial virulence determinats and pathogenesis of Urinary tract infection. Infect Dis Clin North Am 2003; 17:261-78. 